\title{
Investigating different factors for regional market entrance
}

\author{
Ali Ghasemi* and Abohamid Hajipour Shooshtari
}

Department of Management and Accounting, Tehran South Branch, Islamic Azad University, Tehran, Iran

\begin{tabular}{l}
\hline C H R O N I C L E \\
\hline Article history: \\
Received March 18, 2014 \\
Accepted 26 November 2014 \\
Available online \\
November 302014 \\
\hline Keywords: \\
Market entrance \\
Regional market \\
Factor analysis
\end{tabular}
\begin{abstract}
A B S T R A C T
This paper presents an empirical investigation to study the effects of different factors for regional market entrance. The population of this survey includes all producers who are involved in export of industrial goods in city of Tehran, Iran. The study designs a questionnaire in Likert scale and distributes it among some randomly selected experts who were involved in production and export of different products. Cronbach alpha was calculated as 0.856 , which is well above the minimum acceptable level. Using principal component analysis, the study has detected seven factors including product development, government support, strategic orientation, customer satisfaction, competitive pressure, organizational capabilities and distribution strategies influencing on product development. In addition, the implementation of structural equation modeling has determined that product development, government support, strategic orientation and competitive pressure maintained the highest effects on product development.
\end{abstract}

\section{Introduction}

The ability of business marketers to carefully monitor, adopt and manage advanced technologies is an essential predictor of long-term competitiveness. Ghingold and Johnson (1998) developed a framework linking the technical knowledge of an organization's managers to its capability to gain and hold competitive advantage. They presented the proposition that market driven companies with technically knowledgeable managers need to be better positioned to gain and hold competitive advantage. Export is the basis of market development for more developing countries (Albaum et al., 2008; Pettersson \& Galdo Nogales, 2002). Chetty and Campbell-Hunt (2004) identified the consequences of rapid international growth, referred to as "the gusher," among some companies and the destabilizing effects of the experience as the company was taken in unexpected directions. They reported that the bornglobal model had much in common with the internationalization of small entrepreneurial companies and that their most distinctive elements could lie in the framework's relevance to an increasingly globalized world economy and in the more aggressive learning strategies, which were required to follow this path. They also used the business network perspective to determine how small to mediumsized manufacturing companies in a small isolated economy such as New Zealand could deal with the *Corresponding author.

E-mail addresses: ghasemiaali158@gmail.com (A. Ghasemi) 
issues of success and rapid growth as a result of their internationalization efforts. Suárez-Ortega and Álamo-Vera (2005) investigated the particular organizational and managerial determinants of the various characteristics of a firm's export development process: intention, propensity, and intensity. Kaleka (2002) adopted a resource-based view and used it to industrial goods' manufacturers engaged in exporting activities. The notion of organizational process was also implemented as a filtering mechanism for the development of a classificatory scheme for organizations' sources of competitive advantage in export markets. Various combinations of export-related resources and capabilities were detected as drivers of expense, service, and product advantage. However, the ability to build enduring relationships with customers emerged as essential in reaching all three kinds of export competitive advantage. Rettie et al. (2002) reported for the first time that identification of pioneer status was associated with actual purchase of that brand. Pavic et al. (2007) gave some insight about e-business, competitive advantage and their roles in the UK SMEs. Salavou and Halikias (2009) investigated different types of exporting firms featuring strategy orientations and profitability of differential emphasis. Köksal and Özgül (2010) determined the export competitive advantage differences between high- and low-performing companies in Turkey. They specifically analyzed the companies' export resources, export skills, and export competitive advantages in order to determine the discrimination effects of each variable. According to Progoulaki and Theotokas (2010), resource-based view (RBV) may contribute to the confrontation of the hindrances that shipping firms may face in the management of their human resources, and to the formation of sustainable competitive advantage. They analyzed the findings of a field study, regarding the various human resource and crew management practices applied by Greek-owned shipping firms. They also proposed an integrated framework for managing human resources in the shipping industry in a way, which could lead to the formation of sustainable competitive advantage. According to Awuah and Gebrekidan (2008), a firm's highly valued performance, an indication of its strong position or competitive strength, has its roots in its regular and intensive interaction with some substantial actors in its network. Čater and Čater (2009) contributed to the body of knowledge on the antecedents of a firm's competitive advantage and performance by proposing a conceptual model. They reported that a cost advantage was positively influenced by financial resources and customer capital, while a differentiation advantage was positively influenced by financial resources and all three components of intellectual capital. Barney (2001) investigated some of the implications of positioning the resource-based view relative to these other two literatures. Vlahvei et al. (2013) identified the online strategies and the web sites features implemented by the Greek food exporting SMEs in order to establish a strong brand identity in the global market.

\section{The proposed study}

This paper presents an empirical investigation to study the effects of different factors for regional market entrance. The population of this survey includes all producers who are involved in export of industrial goods in city of Tehran, Iran. The study designs a questionnaire in Likert scale and distributes it among some randomly selected experts who were involved in production and export of different products. The sample size is calculated as follows,

$$
n=\frac{N \times z_{\alpha / 2}^{2} \times p \times q}{\varepsilon^{2} \times(N-1)+z_{\alpha / 2}^{2} \times p \times q},
$$

where $N$ is the population size, $p=1-q$ represents the yes/no categories, $z_{\alpha / 2}$ is CDF of normal distribution and finally $\varepsilon$ is the error term. Since we have $p=0.5, z_{\alpha / 2}=1.96$ and $N=856$, the number of sample size is calculated as $n=250$. In our study, we first distributes 40 questionnaire among some experts. . Cronbach alpha was calculated as 0.856 , which is well above the minimum acceptable level.

Fig. 1 demonstrates personal characteristics of the participants. 


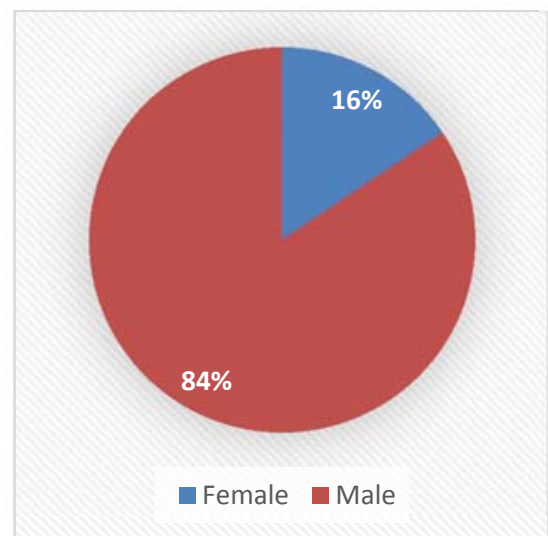

Gender

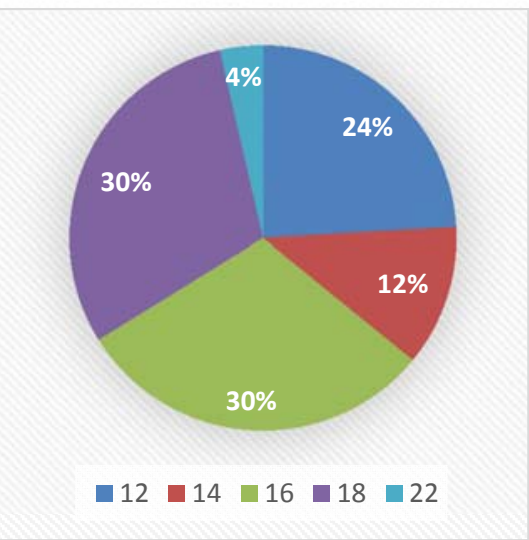

Years of education

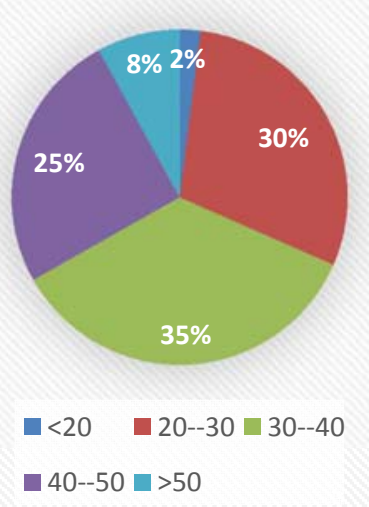

Age

Fig. 1. Personal characteristics of the participants

As we can observe from the results of Fig. 1, most participants are male with good educational background. In addition, they were mostly middle aged people. The proposed study of this paper uses factor analysis using Varimax method. Table 1 demonstrates the results of our survey.

\section{Table 1}

The summary of factor analysis

\begin{tabular}{|c|c|c|c|c|c|c|c|c|c|}
\hline \multirow[t]{2}{*}{ Factor } & \multicolumn{3}{|c|}{ Initial values } & \multicolumn{3}{|c|}{ Extracted values } & \multicolumn{3}{|c|}{$\begin{array}{l}\text { Extracted values } \\
\text { After rotation }\end{array}$} \\
\hline & Total & \%Variance & \%Accumulated & Total & \%Variance & \%Accumulated & Total & \%Variance & \%Accumulated \\
\hline 1 & 7.198 & 19.453 & 19.453 & 7.198 & 19.453 & 19.453 & 4.242 & 11.464 & 11.464 \\
\hline 2 & 3.793 & 10.252 & 29.705 & 3.793 & 10.252 & 29.705 & 3.174 & 8.577 & 20.041 \\
\hline 3 & 2.719 & 7.349 & 37.054 & 2.719 & 7.349 & 37.054 & 2.52 & 6.81 & 26.852 \\
\hline 4 & 1.815 & 4.905 & 41.959 & 1.815 & 4.905 & 41.959 & 2.298 & 6.211 & 33.063 \\
\hline 5 & 1.643 & 4.44 & 46.399 & 1.643 & 4.44 & 46.399 & 1.945 & 5.256 & 38.319 \\
\hline 6 & 1.427 & 3.857 & 50.256 & 1.427 & 3.857 & 50.256 & 1.847 & 4.992 & 43.311 \\
\hline 7 & 1.283 & 3.467 & 53.722 & 1.283 & 3.467 & 53.722 & 1.817 & 4.911 & 48.223 \\
\hline 8 & 1.204 & 3.254 & 56.977 & 1.204 & 3.254 & 56.977 & 1.815 & 4.906 & 53.129 \\
\hline 9 & 1.127 & 3.047 & 60.024 & 1.127 & 3.047 & 60.024 & 1.792 & 4.843 & 57.971 \\
\hline 10 & 1.057 & 2.858 & 62.882 & 1.057 & 2.858 & 62.882 & 1.597 & 4.315 & 62.287 \\
\hline 11 & 1.017 & 2.75 & 65.631 & 1.017 & 2.75 & 65.631 & 1.238 & 3.345 & 65.631 \\
\hline 12 & 0.899 & 2.429 & 68.061 & & & & & & \\
\hline 13 & 0.829 & 2.24 & 70.301 & & & & & & \\
\hline 14 & 0.811 & 2.192 & 72.492 & & & & & & \\
\hline 15 & 0.781 & 2.11 & 74.602 & & & & & & \\
\hline 16 & 0.71 & 1.92 & 76.522 & & & & & & \\
\hline 17 & 0.678 & 1.834 & 78.355 & & & & & & \\
\hline 18 & 0.656 & 1.772 & 80.127 & & & & & & \\
\hline 19 & 0.638 & 1.726 & 81.853 & & & & & & \\
\hline 20 & 0.631 & 1.707 & 83.559 & & & & & & \\
\hline 21 & 0.549 & 1.484 & 85.044 & & & & & & \\
\hline 22 & 0.541 & 1.463 & 86.506 & & & & & & \\
\hline 23 & 0.513 & 1.387 & 87.894 & & & & & & \\
\hline 24 & 0.501 & 1.355 & 89.248 & & & & & & \\
\hline 25 & 0.486 & 1.312 & 90.561 & & & & & & \\
\hline 26 & 0.44 & 1.19 & 91.751 & & & & & & \\
\hline 27 & 0.418 & 1.13 & 92.881 & & & & & & \\
\hline 28 & 0.392 & 1.059 & 93.94 & & & & & & \\
\hline 29 & 0.383 & 1.036 & 94.976 & & & & & & \\
\hline 30 & 0.365 & 0.988 & 95.963 & & & & & & \\
\hline 31 & 0.347 & 0.937 & 96.901 & & & & & & \\
\hline 32 & 0.317 & 0.856 & 97.757 & & & & & & \\
\hline 33 & 0.254 & 0.688 & 98.445 & & & & & & \\
\hline 34 & 0.227 & 0.614 & 99.059 & & & & & & \\
\hline 35 & 0.168 & 0.453 & 99.512 & & & & & & \\
\hline 36 & 0.101 & 0.272 & 99.784 & & & & & & \\
\hline 37 & 0.08 & 0.216 & 100 & & & & & & \\
\hline
\end{tabular}

In addition, we have also used Scree plot to extract the important factors and Fig. 2 demonstrates the results of our survey. As we can observe from the results of Fig. 2, there are seven factors, which could be used for analyzing the export. Table 2 demonstrates the results of seven factors along with its components. 


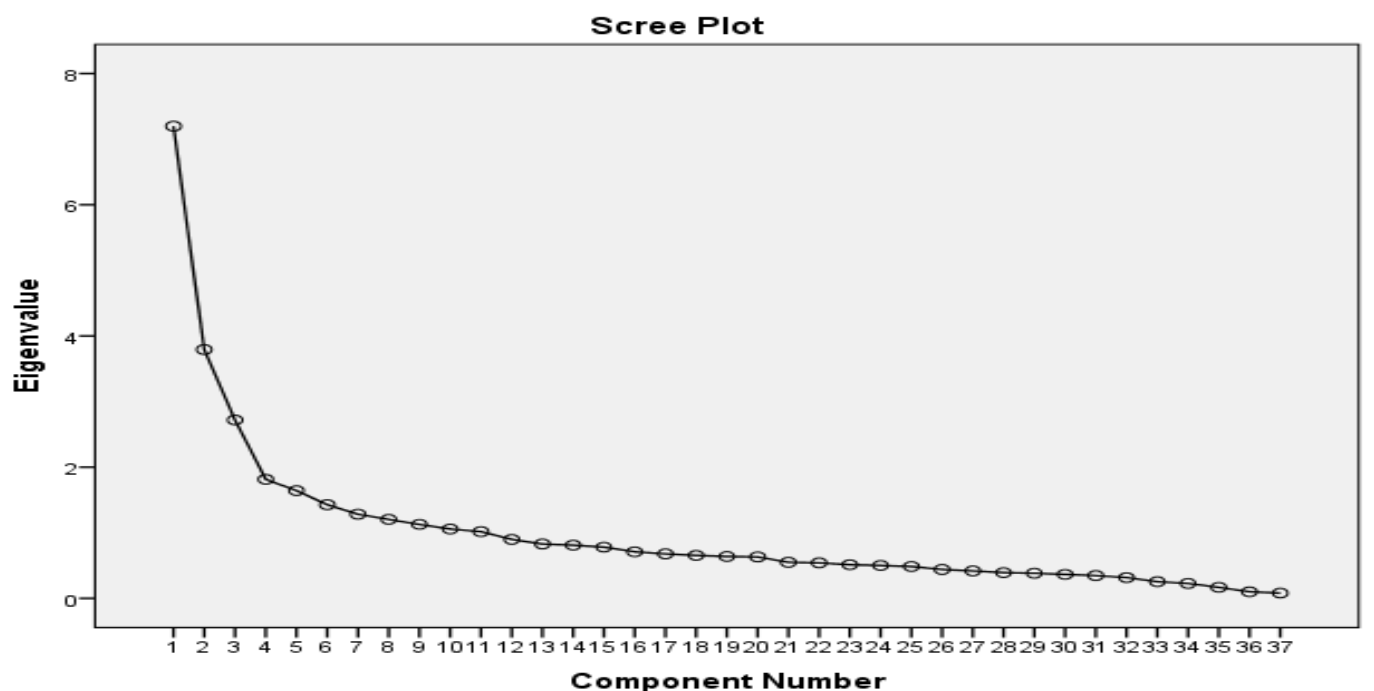

Table 2

Fig. 2. The results of Scree plot

The summary of factors and their components

\begin{tabular}{|c|c|c|c|}
\hline Factor & Question & Description & Factor loading \\
\hline \multirow{8}{*}{ Product development } & $\mathrm{q} 3$ & Research and development & 0.729 \\
\hline & q6 & Innovation in production & 0.705 \\
\hline & q7 & Product life cycle & 0.699 \\
\hline & $\mathrm{q} 2$ & Applying advanced technologies & 0.686 \\
\hline & q1 & Quality of products & 0.646 \\
\hline & q5 & Compatibility of product with market & 0.629 \\
\hline & $\mathrm{q} 4$ & Product diversity & 0.562 \\
\hline & q8 & Packaging & 0.497 \\
\hline \multirow{5}{*}{ Governmental support } & q22 & Customs & 0.792 \\
\hline & $\mathrm{q} 23$ & Giving subsidy for producers & 0.724 \\
\hline & q19 & Tax exemption & 0.693 \\
\hline & $\mathrm{q} 20$ & Government support & 0.685 \\
\hline & $\mathrm{q} 18$ & Currency policy & 0.594 \\
\hline \multirow{4}{*}{ Strategic orientation } & $\mathrm{q} 25$ & Taking part in international exhibitions & 0.86 \\
\hline & q13 & Strategic merger & 0.747 \\
\hline & q26 & Integrated marketing & 0.586 \\
\hline & $\mathrm{q} 14$ & Pricing strategy & 0.561 \\
\hline \multirow{3}{*}{ Customer satisfaction } & q33 & After sales services & 0.731 \\
\hline & $\mathrm{q} 37$ & Customer relationship channels & 0.644 \\
\hline & $\mathrm{q} 34$ & Market segmentation & 0.562 \\
\hline \multirow{3}{*}{ Competitive pressure } & q16 & International competition & 0.655 \\
\hline & q15 & Number of competitors & 0.584 \\
\hline & q9 & Market share & 0.476 \\
\hline \multirow{3}{*}{$\begin{array}{l}\text { Organizational } \\
\text { capability }\end{array}$} & $\mathrm{q} 38$ & Marketing research & 0.715 \\
\hline & q39 & Management commitment for export & 0.713 \\
\hline & $\mathrm{q} 40$ & Human resource management & 0.581 \\
\hline \multirow{3}{*}{ Distribution strategy } & $\mathrm{q} 30$ & Foreign sales representative & 0.731 \\
\hline & q29 & Distribution ownership & 0.591 \\
\hline & q31 & E-commerce & 0.575 \\
\hline
\end{tabular}

Using principal component analysis, the study has detected seven factors including product development, government support, strategic orientation, customer satisfaction, competitive pressure, organizational capabilities and distribution strategies influencing on product development. We have also applied structural equation modeling to examine the effects of various factors detected in this section. After making some changes on the primary model, the final model has been modified and Fig. 3 demonstrates the results of our survey. In our survey, all statistical observations were within acceptable levels and therefore, we may use the results of the model. 


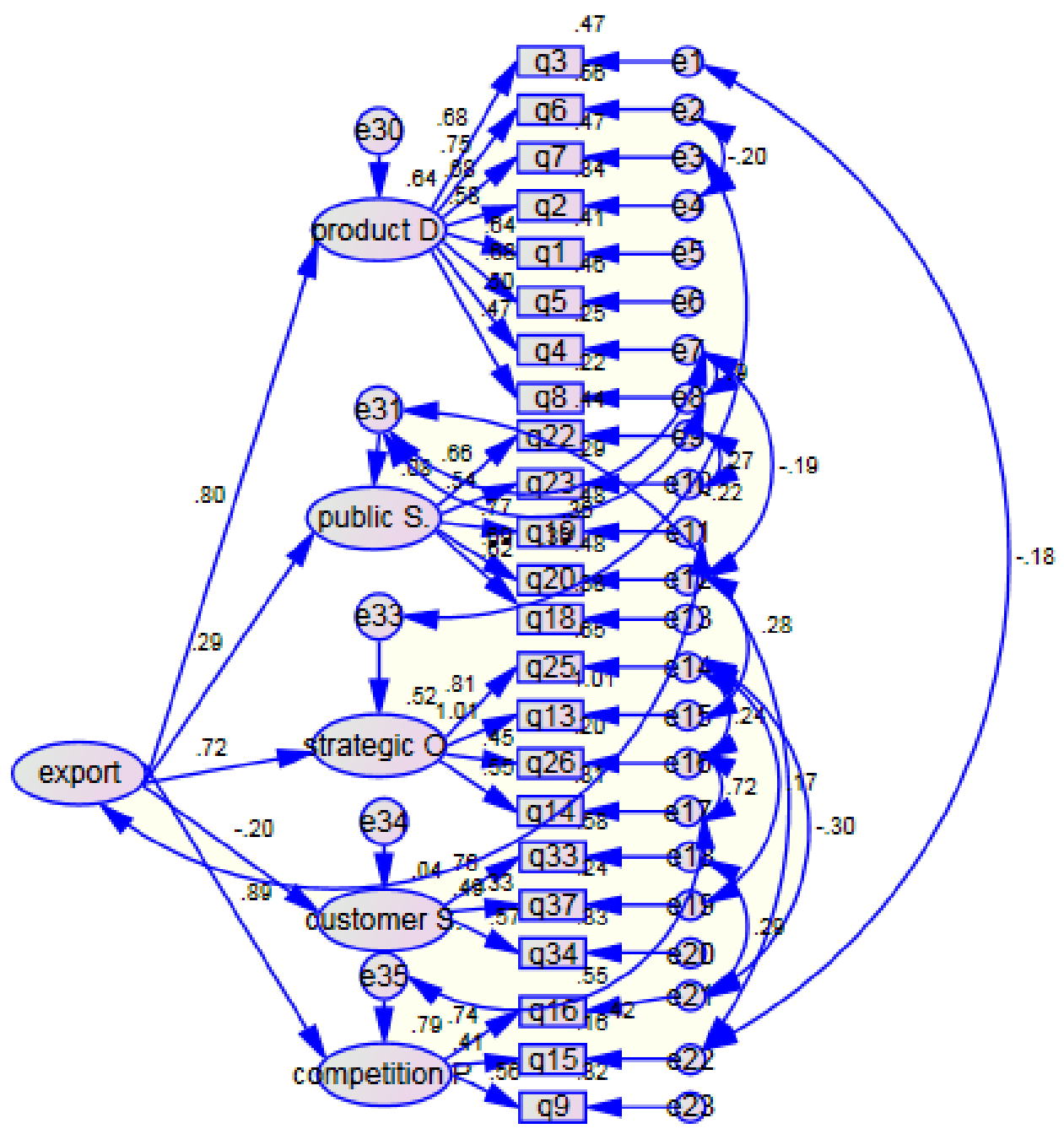

Fig. 3. The results of standard coefficients on structural equation modeling

As we can observe from the results of Fig. 3 product development, government support, strategic orientation and competitive pressure have maintained the highest effects on product development.

\section{Conclusion}

In this study, the role of entry into regional markets in the realization of the brand promise in Iranian industries have been examined. Using principal component analysis, the study has detected seven factors including product development, government support, strategic orientation, customer satisfaction, competitive pressure, organizational capabilities and distribution strategies influencing on product development. In addition, the implementation of structural equation modeling has determined that product development, government support, strategic orientation and competitive pressure maintained the highest effects on product development. Based on the results of this survey, we may recommend the experts who wish to promote export to invest on their research and development. They need to have appropriate data gathering system to collect the necessary marketing information. In fact, production must be aligned with market demand. We also need to setup appropriate macro strategies to develop market in regional market. These days, product life cycles may be influenced by various factors such as the change on people's interests, habits, etc. It is important for experts to learn more about customs and people's tendencies to prepare better marketing strategies. 


\section{Acknowledgement}

The authors would like to thank the anonymous referees for constructive comments on earlier version of this paper.

\section{References}

Albaum, G. S., Albaum, G., \& Duerr, E. (2008). International marketing and export management. Pearson Education.

Awuah, G. B., \& Gebrekidan, D. A. (2008). Networked (interactive) position: a new view of developing and sustaining competitive advantage. Competitiveness Review, 18(4), 333-350.

Barney, J. B. (2001). Resource-based theories of competitive advantage: A ten-year retrospective on the resource-based view. Journal of management,27(6), 643-650.

Čater, T., \& Čater, B. (2009). (In) tangible resources as antecedents of a company's competitive advantage and performance. Journal for East European Management Studies, 14(2), 186-209.

Chetty, S., \& Campbell-Hunt, C. (2003a). Explosive international growth and problems of success amongst small to medium-sized firms. International Small Business Journal, 21(1), 5-27.

Chetty, S., \& Campbell-Hunt, C. (2003b). Paths to internationalisation among small-to medium-sized firms: a global versus regional approach. European Journal of Marketing, 37(5/6), 796-820.

Chetty, S., \& Campbell-Hunt, C. (2004). A strategic approach to internationalization: a traditional versus a "born-global" approach. Journal of International Marketing, 12(1), 57-81.

Ghingold, M., \& Johnson, B. (1998). Intrafirm technical knowledge and competitive advantage: a framework for superior market driven performance.Journal of Business \& Industrial Marketing, 13(1), 70-81.

Kaleka, A. (2002). Resources and capabilities driving competitive advantage in export markets: guidelines for industrial exporters. Industrial Marketing Management, 31(3), 273-283.

Köksal, M. H., \& Özgül, E. (2010). The export competitive advantages of Turkish manufacturing companies. Marketing Intelligence \& Planning, 28(2), 206-222.

Pavic, S. C. L. K., Koh, S. C. L., Simpson, M., \& Padmore, J. (2007). Could e-business create a competitive advantage in UK SMEs?. Benchmarking: An International Journal, 14(3), 320-351.

Pettersson, J., \& Galdo Nogales, N. (2002). How to Improve Export Promotion towards SMEs, with focus on Information provision and Network of main actors. rapport nr.: Masters Thesis, (2001).

Progoulaki, M., \& Theotokas, I. (2010). Human resource management and competitive advantage: An application of resource-based view in the shipping industry. Marine Policy, 34(3), 575-582.

Rettie, R., Hilliar, S., \& Alpert, F. (2002). Pioneer brand advantage with UK consumers. European Journal of Marketing, 36(7/8), 895-911.

Salavou, H. E., \& Halikias, J. (2009). Strategy types of exporting firms: a view on the basis of competitive advantage. European Business Review, 21(2), 144-158.

Suárez-Ortega, S. M., \& Álamo-Vera, F. R. (2005). SMES' internationalization: firms and managerial factors. International Journal of Entrepreneurial Behaviour \& Research, 11(4), 258-279.

Vlahvei, A., Notta, O., \& Grigoriou, E. (2013). Establishing a strong brand identity through a website: The case of Greek Food SMEs. Procedia Economics and Finance, 5, 771-778. 